\title{
An approach to define pedestrian escape routes in evacuation
}

\author{
M. Di Gangi \\ Department of Civil Engineering, University of Messina, Italy
}

\begin{abstract}
This paper considers a method for the definition of pedestrian escape routes by means of the simulation of pedestrian outflow. Feasible solutions are generated and compared in terms of evacuation time. In the proposed method an aggregate model for the estimation of evacuation time of a building is adopted. Such a method can be easily implemented and can be used to give a first evaluation of evacuation procedures without performing evacuation drills and can be used to give a fast response in identifying critical points on the network. To check the capabilities of the models used within the proposed approach, results obtained from simulations are compared with data recorded from an experiment on a test site conducted in a primary school located in an Italian town; an application consisting of designing escape routes for a school is also presented.

Keywords: evacuation, path search, pedestrian.
\end{abstract}

\section{Introduction}

An evacuation can be defined as a general mobilization of people (and/or goods) due to the occurrence of a calamitous event. Its main objective is to reduce the number of people (and/or goods) present in the area where the event strikes [1]. Evacuation drills are mainly performed for people to practice leaving the interested area; these tests can also be used for getting information concerning the behavior of the people in order to build a set of mathematical models able to reproduce the evacuation. These models can constitute a Decision Support System (DSS) to be used for planning emergencies [2].

Simulation models, used to perform quantitative analysis on the operational conditions of a transportation system in emergency circumstances, differ depending on the hypotheses made on the representation of the flow 
characteristics. Among the proposed classifications and reviews, those proposed by Gwynne et al. [3], the Fire Model Survey [4], Kuligowski and Peacock [5] and Olenick and Carpenter [6] can be considered to specify a common terminology, structure and data gathering in order to approach a classification of the models.

Pedestrian evacuation has been considered in the last few years as a lead issue from both theoretical and practical points of view. On the one hand details of pedestrian evacuation have been cast into mathematical formulations yielding various representations of pedestrian interactions [7-13]. On the other hand theoretical developments have been conducted to model emergency evacuation and situations [14-27] using sophisticated simulation methodologies.

The computational complexity of the proposed models requires one to analyze the outflow conditions of the networks, and the adoption of dedicated and sophisticated tools. On the other hand there is also, in certain circumstances, a need for simple tools that are able to quantify, in terms of evacuation time, the effectiveness of an evacuation plan.

Such aggregate approaches, in order to simulate pedestrian movements, consider laws of motion of pedestrian flow using, in general, relationships between speed and density [28-31] or deriving from continuum theory of traffic flows [32, 33].

In this paper a specific methodology (models and procedure) to define effective escape routes by simulating the evacuation of buildings is shown. The proposed aggregate approach allows a prompt first attempt evaluation in case of the lack of commercial software or tools suitable to perform advanced and more sophisticated simulations.

The paper is structured as follows: in Section 2 the proposed method to define the evacuation routes is described in the case of buildings, where a validation of the proposed model to compute the evacuation time comparing results obtained from simulations with recorded data from on-site experiments is also reported. In Section 3 an application to a real case is presented and some remarks are reported in Section 4.

\section{Proposed method}

The proposed methodology can be summarized in the following steps, whose connections are sketched in Figure 1.

1) Definition of the supply model of the building. The building is schematically illustrated considering the network of all possible pathways that are represented by means of the fundamentals of graph theory considering the elements (corridors, stairs, etc.) they are composed of.

2) Definition of escape demand. Starting from data concerning occupants (number and positions), the number of people staying in each area is attributed to the correspondent origin node representing the considered site.

3) Definition of escape route. In this step, the destination assembly point and evacuation routes are defined for each area assumed as the origin of evacuation; considering the graph of the network representing the elements, 
in terms of the components of the escape ways (ramps, corridors, stairs, etc.) of the building, a set of paths connecting each origin with each defined safe destination is generated. In order to explore a wide range of alternatives, for each origin-destination pair more than one evacuation route is taken into consideration. Paths are described as a sequence of elements of the graph obtained from the supply model, as defined above.

4) Generation of evacuation configuration. Starting from the computed set of evacuation routes, feasible evacuation scenarios are built taking account of some selection rules introduced in order to avoid unnatural behaviours.

5) Computation of flow variables and travel times. For the considered scenario, using an aggregate model, travel times and flow characteristics are computed in order to define some indicators on evacuation conditions such as total travel time and evacuation time.

6) Selection of evacuation scenario. The effective scenario is selected considering, among all the simulated configurations, the one that minimizes evacuation time and/or total travel time.

In the following section descriptions concerning the operations conducted and the models considered at each step of the procedure are given.

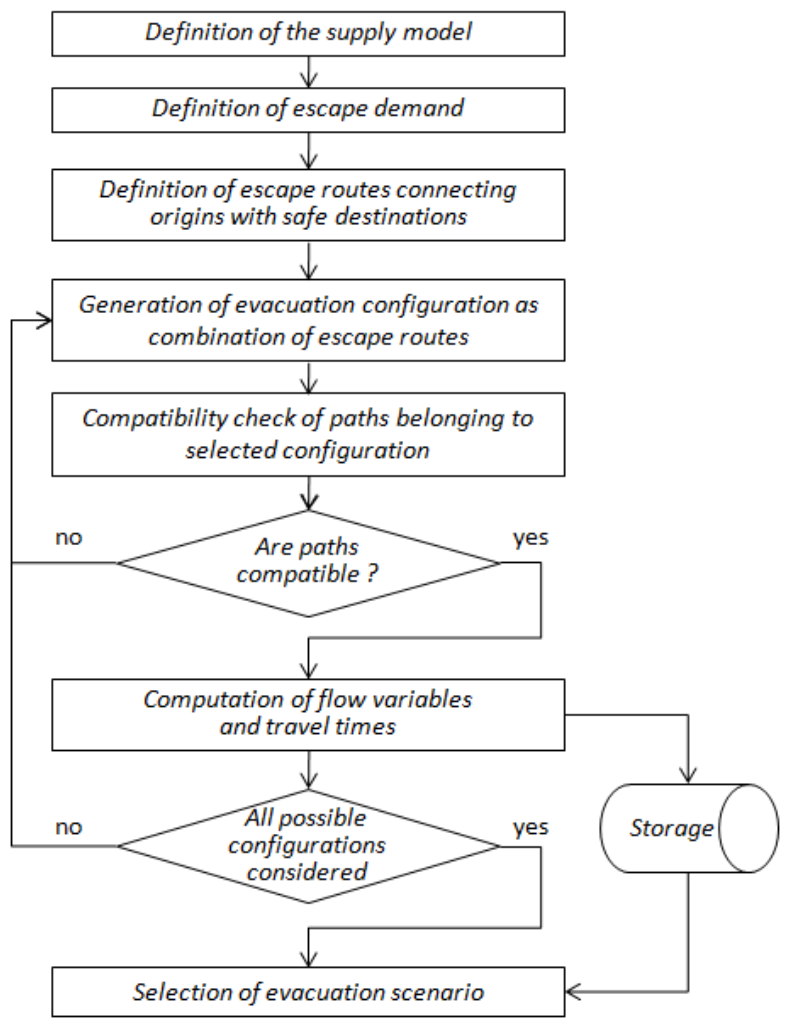

Figure 1: Scheme of the connections among activities. 


\subsection{Definition of the supply model}

In this step the geometric characteristics of elements of the building are acquired; then, considering the elements of a building, the classes of components making up the graphs are:

- area centroids: these nodes represent the barycentre of each area (rooms, offices, etc.) comprising the building. They sum up the origins of the trips of all the people who, at emergency times, are within the area considered. There is a centroid for each area in which the building is divided;

- destination nodes (centroids): these represent the safe areas towards which people converge in an emergency; they correspond to the destinations of each evacuation route;

- network nodes: these are located at each potential change of direction along a generic evacuation route or at significant variations in geometric and/or functional characteristics of a trunk (i.e. width variations);

- real arcs: these represent the connection between two network nodes or a network and a destination node; they coincide with trunks of the pedestrian network and are classified into flat ramps (corridors) and descending or ascending ramps (stairs);

- connector arcs: these represent the connection between a centroid and a network node.

\subsection{Definition of escape demand}

In this step, data concerning occupants, defining both their number and their positions, are acquired. Those values are attributed to the correspondent origin nodes representing each considered site. Different scenarios should be considered for the analysis of evacuation considering different distributions of occupants.

\subsection{Path generation}

After building the graph of the network representing the elements, in terms of components of the escape ways (ramps, corridors, stairs, etc.) of the building, a set of evacuation routes connecting each origin with each defined safe destination is generated. In order to explore a wide range of alternatives, for each origin-destination pair more than one path is taken into consideration. To define these evacuation routes a set of paths is generated considering a $\mathrm{K}$ shortest loopless path algorithm. An analysis of such algorithms is beyond the bounds of this paper; anyway one of the most used algorithms is the one proposed by Yen [34]; interested readers can find the necessary insights on the matter in Gallo and Pallottino [35] and a review of the bibliography can be found on a web page edited by Eppstein [36].

One of the possibilities in order to take into account the environmental conditions of each link within conventional path search algorithms can be to weight travel time associated to the generic arc of the graph by means of the 
level of risk associated to the arc [37], assuming that the role of risk can be associated similarly to the one played by the saturation level in congested networks.

\subsection{Generation of alternatives}

The number of alternative is strictly influenced by the value assumed by $\mathrm{k}$, denoting the number of alternative evacuation routes considered for each origin/destination pair, since the number of potential alternatives is given by the permutation of the $\mathrm{k}$ paths on $\mathrm{N}_{\mathrm{od}}$ origin/destination pairs, that is $\mathrm{N}_{\mathrm{od}}{ }^{\mathrm{k}}$

The scenario is generated by applying a selection rule to the set given by the combination of paths for each o/d pair. The rule here, introduced in order to define the feasibility of a combination, consists of eliminating those combinations where contra flow is potentially allowed, that is, each element of the network (ramp, corridor, stair, etc) must be covered in one direction.

In order to establish feasibility, given a path $\mathrm{k}$ let $\mathrm{l}_{\mathrm{k}}(\mathrm{r}, \mathrm{s})$ be a generic link belonging to the path $\mathrm{k}$ connecting nodes $\mathrm{r}$ and $\mathrm{s}$; path $\mathrm{h}$ and path $\mathrm{k}$ are compatible if considering each link $\mathrm{l}_{\mathrm{h}}(\mathrm{r}, \mathrm{s})$ a link $\mathrm{l}_{\mathrm{k}}(\mathrm{s}, \mathrm{r})$ does not exist, that is, no link of path $k$ corresponds to the opposite of links of path $h$.

Such a rule is implemented by defining an incidence matrix $C\left[\begin{array}{lll}n_{k} & \times n_{k}\end{array}\right]$ of compatibility among paths where the generic element $c_{h k}$ is equal to 1 if path $\mathrm{h}$ and path $\mathrm{k}$ are compatible, and 0 otherwise. So a combination of paths is feasible if each path is compatible with the other ones belonging to the considered combination.

\subsection{Computing evacuation time}

The adopted method, recently proposed [38], can be summarized through a succession of operations finalized by the evaluation of evacuation time. Such operations are listed in the following:

\section{Demand-Supply Interaction Model}

- Computation of occupants for each element $q_{i}$. For each element of the escape routes, the flow of occupants is computed using the arc-path incidence matrix $(\boldsymbol{A})$ as $\boldsymbol{q}=\boldsymbol{A d}$.

- $\quad$ Computation of the specific flow $\left(q_{s}\right)$. This value is computed dividing flow $q$ by the effective width $w$ of the considered element except for connectors; for those latter components specific relationships based on density are adopted.

- Computation of speed. Once specific flow $q_{s}$ is known, the following two cases arise:

- values of $q_{s}$ do not reach the value $q_{s}^{\text {max }}$ of characteristic maximum specific flow for the considered element; speed $v$ ' is computed using specific relationships depending on specific flow;

- values of $q_{s}$ overtake the value $q_{s}^{\max }$ of characteristic maximum specific flow for the considered element; in this case queues arise in correspondence with the transition points; the correspondent speed $v$ '” is 
given by the limit value indicated by relationships expressing speeds depending on specific flow.

\section{Computation of times}

- Computation of flow time for each element $\left(t f_{i}\right)$. Those values are computed once walking speed is evaluated for each considered element as $t f_{i}=l_{i} / v_{i}$.

- Computation of queue time for each element $\left(t q_{i}\right)$. Those values are computed depending on the specific flow $q_{s}$ and the value $q_{s}^{\max }$ of the characteristic maximum specific flow for the considered element as $t q_{i}=\left(q_{s}\right.$ $\left.-q_{s}^{\max }\right) / q_{s}^{\max }$.

- Computation of travel time for each escape route (T). Travel times are computed, for the whole set of evacuation routes, considering the arc-path incidence matrix as $\boldsymbol{T}=\boldsymbol{A}^{T}\left(\boldsymbol{t}_{\boldsymbol{f}}+\boldsymbol{t}_{\boldsymbol{q}}\right)$.

- Computation of evacuation time. After computing travel time for each evacuation route, the higher value $T$ among all the travel times is considered as the evacuation time.

This methodology has been calibrated in a real context [56] where evacuation drills have been carried out in order to collect data to validate the proposed models.

\section{Applicative context}

\subsection{The test site}

The considered building is a primary school located within the CBD area selected for the drill [39]. The school evacuation plan stipulates that everybody must gather at a site in front of the building (called the first assembly point, see Figure 2); according to the town evacuation plan, the school's staff and pupils will be led to the refuge area by means of a bus service starting from another gathering place (the second assembly point). In the application described here the analysis focuses on the evacuation of the building to the first assembly point.

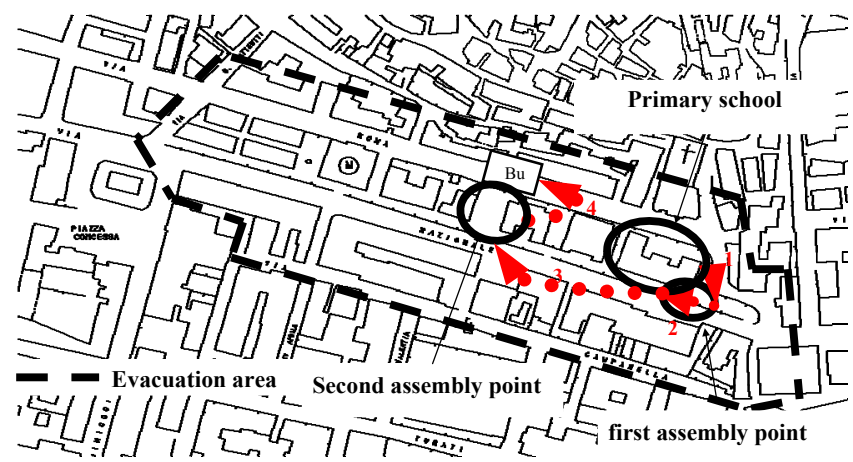

Figure 2: $\quad$ Phases of evacuation. 
Data were gathered concerning supply and demand. During the drill a monitoring system was arranged, with manual/automatic tools and 12 video cameras, in order to acquire data concerning pedestrian outflow (times, densities) both inside and outside the building until the gathering places were reached.

\subsection{Simulations}

Demand values used in the simulations were obtained from school attendance on the day of the experiment, and users were located in offices and classrooms following the real distribution. There were about 150 users.

The evacuation of the first phase has been simulated considering escape routes obtained from the school evacuation plan. Two different simulations have been conducted. The first simulation, realised applying a Dynamic Traffic Assignment (DTA) mesoscopic model [40-42], has been performed, and in this case, for fictitious links a constant speed function was considered whilst for corridors and descending flights relationships between speed and specific flow specified and calibrated in [43] have been considered.

The second simulation has been performed applying to the building the aggregate procedure described in Section 2.5 where queue time has been taken into consideration [38].

Some investigations can be made into these approaches. For the first one (mesoscopic approach) the main advantage consists of the possibility to explicitly simulate queues and spill backs, whilst a drawback is given by the necessity to use a specific software. The second approach (macroscopic) gives an aggregate representation of flow conditions and does not allow their detailed analysis; on the other hand it can be easily implemented on a spreadsheet.

Results obtained from the application of the above-described approaches have been expressed in terms of evacuation time. In Table 1 evacuation times for the considered phase related to experiments and to simulations are reported.

Table 1: Comparison of the evacuation times obtained from the drill with the simulated times.

\begin{tabular}{cccc}
\hline Phase & $\begin{array}{c}\text { Measured } \\
\text { time }\end{array}$ & $\begin{array}{c}\text { Meso } \\
\text { simulation }\end{array}$ & $\begin{array}{c}\text { Aggregate } \\
\text { simulation }\end{array}$ \\
\hline 1) evacuation of the building reaching first assembly point & 4'14,, & $5^{\prime}, 47^{\prime}$, & 7'30', \\
\hline
\end{tabular}

\subsection{Design of escape routes}

Results obtained in the previous section concern the schematization of the network of the building, sketched in Figure 3, and escape routes obtained from the school evacuation plan, as described in Table 2.

The application of the design procedure, considering two paths for each O/D pair, generates eight possible scenarios of which five are feasible. It yields a slightly different configuration of the evacuation routes, as described in Table 3. 

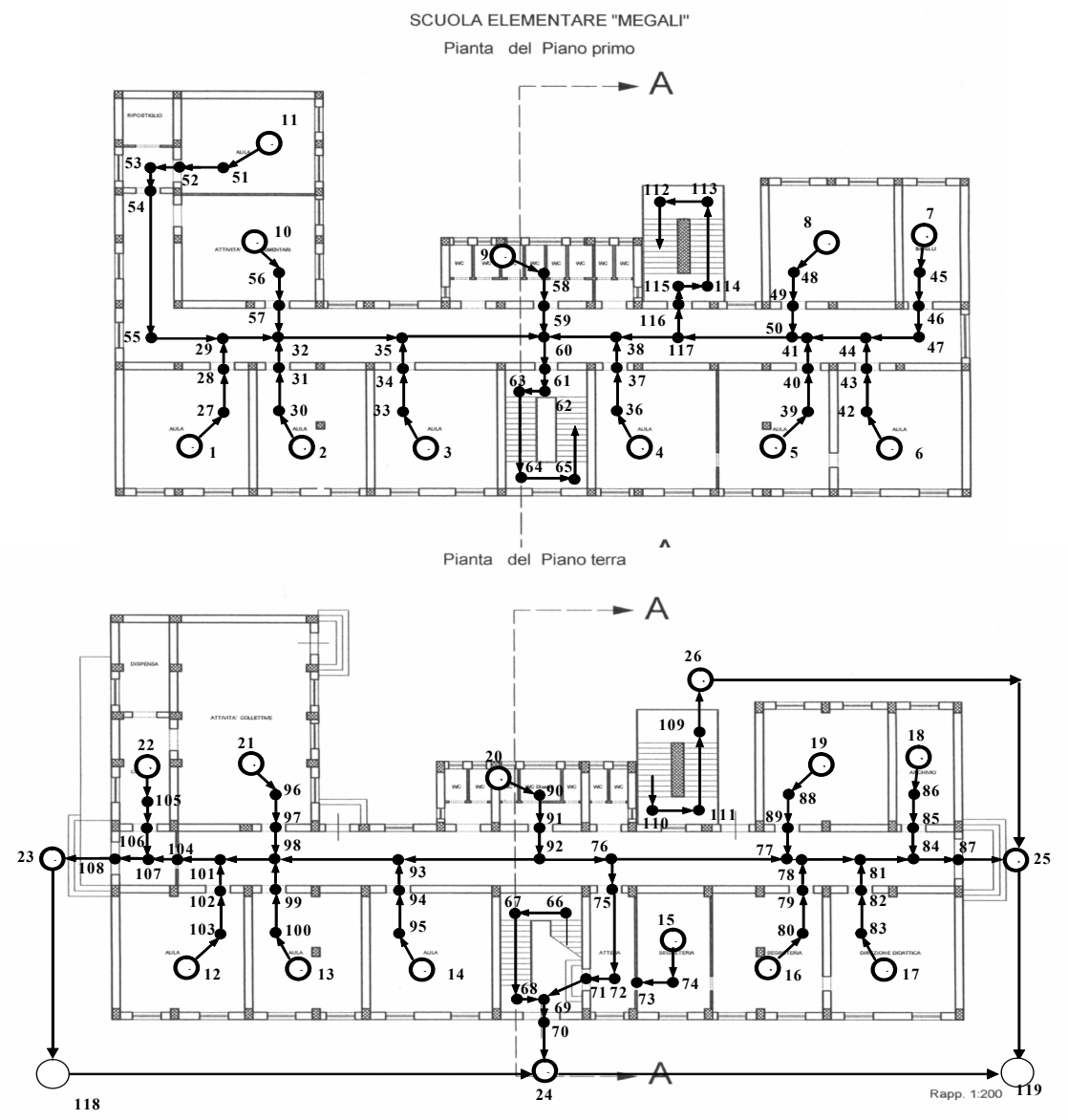

Figure 3: Graph of the ground floor and first floor considered for the simulations of the evacuation.

Table 2: Succession of nodes of the escape routes from the school evacuation plan.

\begin{tabular}{c|cccccccccccccccccccc}
\hline OD & \multicolumn{11}{|c}{ Succession of nodes } \\
\hline $\mathbf{1}$ & 1 & 27 & 28 & 29 & 32 & 35 & 60 & 61 & 62 & 63 & 64 & 65 & 66 & 67 & 68 & 69 & 70 & 24 & 119 \\
$\mathbf{2}$ & 2 & 30 & 31 & 32 & 35 & 60 & 61 & 62 & 63 & 64 & 65 & 66 & 67 & 68 & 69 & 70 & 24 & 119 & \\
$\mathbf{3}$ & 3 & 33 & 34 & 35 & 60 & 61 & 62 & 63 & 64 & 65 & 66 & 67 & 68 & 69 & 70 & 24 & 119 & & \\
$\mathbf{4}$ & 4 & 36 & 37 & 38 & 117 & 116 & 115 & 114 & 113 & 112 & 110 & 111 & 109 & 26 & 25 & 119 & & & \\
$\mathbf{5}$ & 6 & 42 & 43 & 44 & 41 & 50 & 117 & 116 & 115 & 114 & 113 & 112 & 110 & 111 & 109 & 26 & 25 & 119 & \\
$\mathbf{6}$ & 8 & 48 & 49 & 50 & 117 & 116 & 115 & 114 & 113 & 112 & 110 & 111 & 109 & 26 & 25 & 119 & & \\
$\mathbf{7}$ & 15 & 74 & 73 & 72 & 71 & 69 & 70 & 24 & 119 & & & & & & & & & \\
$\mathbf{8}$ & 16 & 80 & 79 & 78 & 81 & 84 & 87 & 25 & 119 & & & & & & & & & \\
$\mathbf{9}$ & 17 & 83 & 82 & 81 & 84 & 87 & 25 & 119 & & & & & & & & & & \\
\hline
\end{tabular}


Table 3: Succession of nodes of the escape routes from the design procedure.

\begin{tabular}{c|ccccccccccccccccccc}
\hline OD & \multicolumn{11}{|c}{ Succession of nodes } \\
\hline $\mathbf{1}$ & 1 & 27 & 28 & 29 & 32 & 35 & 60 & 61 & 62 & 63 & 64 & 65 & 66 & 67 & 68 & 69 & 70 & 24 & 119 \\
$\mathbf{2}$ & 2 & 30 & 31 & 32 & 35 & 60 & 61 & 62 & 63 & 64 & 65 & 66 & 67 & 68 & 69 & 70 & 24 & 119 & \\
$\mathbf{3}$ & 3 & 33 & 34 & 35 & 60 & 61 & 62 & 63 & 64 & 65 & 66 & 67 & 68 & 69 & 70 & 24 & 119 & & \\
$\mathbf{4}$ & $\mathbf{4}$ & $\mathbf{3 6}$ & $\mathbf{3 7}$ & $\mathbf{3 8}$ & $\mathbf{6 0}$ & $\mathbf{6 1}$ & $\mathbf{6 2}$ & $\mathbf{6 3}$ & $\mathbf{6 4}$ & $\mathbf{6 5}$ & $\mathbf{6 6}$ & $\mathbf{6 7}$ & $\mathbf{6 8}$ & $\mathbf{6 9}$ & $\mathbf{7 0}$ & $\mathbf{2 4}$ & $\mathbf{1 1 9}$ & & \\
$\mathbf{5}$ & 6 & 42 & 43 & 44 & 41 & 50 & 117 & 116 & 115 & 114 & 113 & 112 & 110 & 111 & 109 & 26 & 25 & 119 & \\
$\mathbf{6}$ & 8 & 48 & 49 & 50 & 117 & 116 & 115 & 114 & 113 & 112 & 110 & 111 & 109 & 26 & 25 & 119 & & & \\
$\mathbf{7}$ & 15 & 74 & 73 & 72 & 71 & 69 & 70 & 24 & 119 & & & & & & & & & \\
$\mathbf{8}$ & 16 & 80 & 79 & 78 & 81 & 84 & 87 & 25 & 119 & & & & & & & & & \\
$\mathbf{9}$ & 17 & 83 & 82 & 81 & 84 & 87 & 25 & 119 & & & & & & & & & & \\
\hline
\end{tabular}

\subsection{Comparison of results}

The design procedure has been applied considering two paths for each O/D pair and, due to the aspect of the graph, eight possible scenarios are available and only five of them are feasible. The evacuation time computed considering the escape routes obtained from the evacuation plan (Table 2) has been compared with the one obtained considering the escape routes from the proposed approach (Table 3 ). The results are summarized in Table 4 . The new set of paths allows a reduction of about the $25 \%$ in evacuation time and of about one third in total time, which is the sum of time spent by each user on the network, despite the fact that time spent in queues increased. This means that the new path allows the saving of an amount of time that compensates for the time spent in queues.

Table 4: Comparison of the evacuation time obtained considering escape routes from the evacuation plan and design procedure.

\begin{tabular}{cccc}
\hline & $\begin{array}{c}\text { Evacuation } \\
\text { plan } \\
{[\mathrm{h}: \mathrm{m}: \mathrm{s}]}\end{array}$ & $\begin{array}{c}\text { Design } \\
\text { procedure } \\
{[\mathrm{h}: \mathrm{m}: \mathrm{s}]}\end{array}$ & $\begin{array}{c}\text { Evacuation plan } \\
\text { vs. } \\
\text { Design procedure }\end{array}$ \\
\hline Evacuation time & $00: 07: 30$ & $00: 05: 29$ & $26.9 \%$ \\
Total time & $16: 15: 19$ & $10: 50: 37$ & $33.3 \%$ \\
Max time spent in queue & $00: 01: 05$ & $00: 01: 33$ & $-42.8 \%$ \\
\hline
\end{tabular}

\section{Conclusions and perspectives}

The main result of this paper concerns the application of an aggregate method to design effective evacuation routes and the specification of some cost functions adopted to evaluate, in an aggregate way, the effect of queues. A comparison between experimental data and simulation results shows how the usage of appropriate simulation models can realistically reproduce user behavior. It was shown that such models could be used as a support both to verify effectiveness of existing evacuation plans without resorting to expensive drills and to draw up evacuation plans. Implementation of appropriate cost functions can make the applied methodologies suitable for any building and/or area with homogeneous 
characteristics in terms of activities. Further investigations on travel time functions are under development.

\section{References}

[1] Russo, F., Vitetta, A., Risk evaluation in a transportation system. International Journal of Sustainable Development and Planning, 1 (2), 2006, pp. 170-191.

[2] Russo F., Rindone C., Evaluation methods for evacuation planning. Proc. of Urban Transport XVI, Urban Transport and the Environment in the 21st century, Brebbia C. A. (ed.), WIT Press, Southampton, 2010, pp. 335-343.

[3] Gwynne, S., Galea, E.R., Lawrence, P.J., Owen, M. and Filippidis, L. A review of the Methodologies used in the Computer Simulation of Evacuation from the Built Environment. Building and Environment, 34, 1999, pp. 741-749.

[4] Fire Model Survey. International Survey of Computer Models for Fire and Smoke [on line] http://www.firemodelsurvey.com/EgressModels.html. Updated 2007.

[5] Kuligowski, E.D. and Peacock R.D. A Review of Building Evacuation Models. Technical note n. 1471. National Institute of Standards and Technology, Gaithesburgh, MD, 2005.

[6] Olenick, S.M., Carpenter D.J. An updated international survey of computer models for fire and smoke, Journal of Fire Protection Engineering 13, 2003, pp. 87-110.

[7] C. Burstedde, K. Klauck, A. Schadschneider, J. Zittartz, Simulation of pedestrian dynamics using a two-dimensional cellular automaton, Physica A 295 (2001) 507_525.

[8] W. Yuan, K.H. Tan, A novel algorithm of simulating multi-velocity evacuation based on cellular automata modeling and tenability condition, Physica A 379 (2007) 250_262.

[9] L.Z. Yang, D.L. Zhao, J. Li, T.Y. Fang, Simulation of the kin behavior in building occupant evacuation based on cellular automaton, Building and Environment 40 (2005) 411_415.

[10] Y. Tajima, K. Takimoto, T. Nagatani, Pattern formation and jamming transition in pedestrian counter flow, Physica A 313 (2002) 709 723.

[11] D. Helbing, M. Isobe, T. Nagatani, K. Takimoto, Lattice gas simulation of experimentally studied evacuation dynamics, Physical Review E 67 (2003) 067101.

[12] M. Isobe, T. Adachi, T. Nagatani, Experiment and simulation of pedestrian counter flow, Physica A 336 (2004) 638_650.

[13] D. Helbing, P. Molnár, Social force model for pedestrian dynamics, Physical Review E 51 (1995) 4282_4286.

[14] ASERI (Advance Simulation of Evacuation of Real Individuals) A model to simulate evacuation and egress movement based on individual behavioural response, 2004. http://www.ist-net.de [On-line]. 
[15] Parke, J., Gwynne, S., Galea, E. R., and Lawrence, P. Validating the buildingEXODUS Evacuation Model using Data from an Unannounced Trial Evacuation. In E.R. Galea, Editor, Proceedings of 2nd international pedestrian and evacuation dynamics conference, CMS Press, Greenwich, UK (2003) ISBN 1904521088, pp. 295-306.

[16] Fraser-Mitchell, J. Simulated Evacuations of an Airport Terminal Building, Using the CRISP Model. In 2nd International Symposium in Human Behaviour in Fire (pp. 89-100). Boston, MA, 2001.

[17] Ketchell, N., Cole, S. S., and Webber, D. M. The EGRESS Code for Human Movement and Behaviour in Emergency Evacuation. In R.A.Smith and J. F. Dickie (Eds.), Engineering for Crowd Safety (pp. 361-370). London: Elsevier, 1994.

[18] Francis, R. L. and Saunders, P. B. EVACNET: Prototype Network Optimization Models for Building Evacuation (Rep. No. NBSIR 791593). Natl. Bur. Stand., (U.S.), 1979.

[19] Fahy, R. F. EXIT89 - An Evacuation Model for High-rise Buildings Model Description and Example Applications. In Fire Safety Science Proceedings of the 4th International Symposium (pp. 657-668), 1994.

[20] Levin, B. M. EXITT - A Simulation Model of Occupant Decisions and Actions in Residential Fires. In Fire Safety Science - Proceedings of the Second International Symposium (pp. 561-570), 1988.

[21] Bensilum, M. and Purser, D. A. Gridflow: an object-oriented building evacuation model combining pre-movement and movement behaviours for performance-based design. In 7th International Symposium on Fire Safety Science Worcester, MA: Worcester Polytechnic Institute, 2002.

[22] Berrou, J.L., Beecham, J., Quaglia, P., Kagarlis, M.A., Gerodimos, A. Calibration and validation of the Legion simulation model using empirical data. On line publication http://www.legion.com/aboutus/Publications.php, 2005.

[23] Cappuccio, J. Pathfinder: A Computer-Based Timed Egress Simulation. FireProtection Engineering, 8, 11-12, 2000.

[24] Klupfel, H. and Meyer- König, T. Characteristics of the PedGo Software for Crowd Movement and Egress Simulation. . In E.R. Galea, Editor, Proceedings of 2 nd international pedestrian and evacuation dynamics conference, CMS Press, Greenwich, UK ISBN 1904521088 (pp. 331340), 2003.

[25] Buckmann, L. T. and Leather, J. Modelling Station Congestion the PEDROUTE Way. Traffic Engineering and Control, 35, 373-377, 1994.

[26] Barton, J. and Leather, J. Paxport - Passenger and Crowd Simulation. Passenger Terminal '95, 71-77, 1995.

[27] Di Gangi, M., Russo, F. and Vitetta, A., A mesoscopic method for evacuation simulation on passenger ships: models and algorithms. In Pedestrian and Evacuation Dynamics 2003, pp. 197-208 CMS Press, London ISBN 1-904521-08-8, 2003.

[28] Proulx, G., Evacuation time and movement in apartment buildings, Fire Safety Journal Volume 24, Issue 3, 1995, pp. 229-246. 
[29] Smith, R.A., Density, velocity and flow relationships for closely packed crowds, Safety Science Volume 18, Issue 4, 1995, pp. 321-327.

[30] Fang, Z., Lob, S.M., Luc, J.A. On the relationship between crowd density and movement velocity. Fire Safety Journal Volume 38, Issue 3, 2003, pp. 271-283.

[31] Kholshevnikov, V.V., Shields T.J., Boyce, K.E., Samoshin, D.A. Recent developments in pedestrian flow theory and research in Russia Fire Safety Journal No. 43, 2008, pp. 108-118.

[32] Hughes, R.L., A continuum theory for the flow of pedestrians, Transportation Research Part B, Elsevier, No. 36, 2002, pp. 507-535.

[33] Huang, L.,Wong, S.C., Zhang, M., Shu, C., Lam, W.H.K. Revisiting Hughes' dynamic continuum model for pedestrian flow and the development of an efficient solution algorithm, Transportation Research Part B, Elsevier, No. 43(1), 2009, pp. 127-141.

[34] Yen, J. Y. The k shortest loopless paths in a network. Management science Vol. 17, No. 11, 1971, pp. 712-716.

[35] Gallo G., Pallottino S. Shortest path algorithms. Annals of Operational Research 13, 1988, pp 3-79.

[36] Eppstein D. Bibliography on algorithms for k shortest paths, updated until 2001, http://liinwww.ira.uka.de/bibliography/Theory/k-path.html

[37] Di Gangi M., Evaluation of reliable path in risk areas, in Risk Analysis $V$. Southampton, U.K.: WIT Press, 2006, pp. 371-377.

[38] Di Gangi, M., Rindone, C., An aggregate approach to simulate evacuation of a building. Presented in the Sustainable Development and Planning 2011 Conference, July 2011, New Forest. Forthcoming in Sustainability Today, WIT Press, 2012.

[39] Di Gangi M., Musolino G., Rindone C., Vitetta A., An italian project for exposure reduction in an urban area: experimentation design and DSS development. Proceedings of European Transport Conference. Strasbourg, Sept. 2006, ISBN/ISSN: 1-905701-01-2, 2006.

[40] Di Gangi, M., Approaching the analysis of transport networks in emergency conditions for the design of evacuation plans. In Risk Analysis $I V, 2004$, pp. 485-494, WIT Press. ISBN 1-85312-736-1.

[41] Di Gangi M., Planning Evacuation by Means of a Multi-modal Mesoscopic Dynamic Traffic Simulation Model. B. Murgante, G. Borruso, A. Lapucci (Eds.): Geocomputation and Urban Planning, SCI 176, 2009, pp. 99-115. Springer-Verlag Berlin Heidelberg ISBN: 978-3540-89929-7.

[42] Di Gangi M., Velonà P., Multimodal mesoscopic approach in modelling pedestrian evacuation Transportation Research Record, vol. 2090, 2009; p. 51-58, ISSN: 0361-1981, doi: 10.3141/2090-06.

[43] Di Gangi, M., Modeling Evacuation of a Transport System: Application of a Multimodal Mesoscopic Dynamic Traffic Assignment Model Intelligent Transportation Systems, IEEE Transactions on, vol. 12, Issue 4, 2011, pp. 1157-1166 doi: 10.1109/TITS.2011.2143408. 